\title{
Effect of Using External Vertical Fins in Phase Change Material Modules for Domestic Hot Water Tanks.
}

\author{
Albert Castell ${ }^{1}$, Cristian Solé ${ }^{1}$, Marc Medrano ${ }^{1}$, Joan Roca ${ }^{1}$, Daniel García ${ }^{2}$, Luisa F. Cabeza ${ }^{1}$ \\ ${ }^{1}$ Dept. d'Informàtica i Eng. Industrial, Universitat de Lleida \\ Pere de Cabrera s/n, 25001 Lleida, Spain \\ Tel. +34 973003576, Fax.+34 973003575, e-mail: acastell@diei.udl.es, csole@diei.udl.es, \\ mmedrano@diei.udl.es, iroca@diei.udl.es, Icabeza@diei.udl.es \\ ${ }^{2}$ Engineering Projects Dept., Polytechnic University of Catalonia \\ Colom 11, 08222 Terrassa, Spain \\ Tel.+34 937398921, e-mail: daniel.garcia@upc.edu
}

\begin{abstract}
The effect of using external vertical fins in Phase Change Materials (PCM) modules to improve the natural convection coefficient in water is studied in this paper.
\end{abstract}

The use of PCM in a water tank working with a solar system is able to store a lot of energy, but it is necessary to transfer this energy to the water during demand.

Optimization of the natural convection to the water is of great importance for the heat transfer. External fins increase the heat transfer surface and the heat transfer coefficient changes.

Experimental work was carried out to determine natural convection heat transfer coefficients for PCM modules with two different external vertical fin geometries. Results were presented as a temperature variation over time of the PCM and the water, and the heat transfer coefficient as a function of the temperature difference for different fins.

These results were used to validate a simulation code to determine the behaviour of the system using finned PCM modules. The results prove the technical potential of external fins for heat storage systems using PCM.

The experimental results were used to determine different correlations for Nusselt number as a function of different dimensionless numbers.

\section{Key Words}

Phase Change Material (PCM), Fins, Natural convection, Solar Energy, Nusselt Number, Experimental correlations.

\section{Introduction}

When using renewable energies, the difference between hot water availability and consumption increases the importance of thermal energy storage systems. Latent heat thermal storage has become a promising technology.

Latent heat thermal storage uses Phase Change Materials (PCM) to provide a higher energy density to thermal systems. Their use in Domestic Hot Water (DHW) tanks would supply hot water for a longer time.

The use of PCM in a water tank working with a solar system has been studied in previous works $[1,2]$. This technology is able to store a lot of energy, but it is necessary to transfer this energy to the water during demand, therefore heat transfer within the $\mathrm{PCM}$ and to the water is of high interest.

PCM composites and modules have been optimized to enhance the heat transfer $[3,4]$, but natural convection from the PCM to the water have not. External fins increase the heat transfer surface and the heat transfer coefficient changes.

Fins geometry is very important to enhance the heat transfer coefficient. Two different geometries have been studied: horizontal and vertical fins. There is much more literature about horizontal fins [5-23] but this geometry interferes natural convection in the water. No literature is available for vertical fins around circular vertical cylinders, but this geometry improves the natural convection of the system. Therefore, in this work external vertical fins have been attached to the PCM module.

Previous work has been done introducing PCM modules in DHW solar systems [1,2]. Four PCM modules were introduced in a $146 \mathrm{~L}$ tank connected to two solar collectors and the performance of the systems was tested. 
The objective of this work is to study the effect of adding external vertical fins in the PCM modules. Since there is no correlation in the literature to evaluate the natural convection heat transfer coefficient for the specific geometry studied, experimental set-up has been designed and performed.

\section{Analytical solution}

\section{A. PCM modules without fins}

To study the behavior of the storage system, an energy balance of the water was done. This balance considers the following parameters:

- Heat transfer rate from the PCM to the water

- Heat transfer rate from the upper to the lower layer of water

- Heat losses from the water to the ambient air

- Increase of the water temperature

To evaluate each term of the balance, experimental correlations found in the literature were used.

\section{B. PCM modules with external vertical fins}

The procedure to study the behavior of the PCM modules with external vertical fins is the same used for PCM modules without fins.

\section{Experimental work}

\section{A. Geometry}

To determinate the natural convection heat transfer coefficient additional experiments were necessary. The geometry of the PCM modules is the same used in other experimental work done by the authors [24,25]. These modules are cylindrical, with a diameter of $88 \mathrm{~mm}$ and $315 \mathrm{~mm}$ high.

Two different fins profiles have been analyzed to determine the influence of the heat transfer surface to the water. The first one with $20 \mathrm{~mm}$ fins, the second one with $40 \mathrm{~mm}$ fins, and both $310 \mathrm{~mm}$ high. Fig. 1 shows the PCM modules geometry.

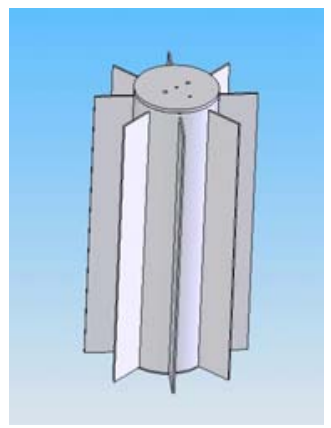

Fig. 1. Module with external vertical fins.
Each module had eight external fins, providing a $28,45 \%$ and $44,28 \%$ transfer surface increase respectively compared to the reference module without fins.

\section{B. Experimental work}

Experimental work consisted in simulating a storage tank with PCM modules inside. Temperature of the $\mathrm{PCM}$ and the water were registered for three different experiments: first one used modules without fins, another one used modules with $20 \mathrm{~mm}$ fins, and the last one used modules with $40 \mathrm{~mm}$ fins.

Tank used was $440 \mathrm{~mm}$ of diameter and $450 \mathrm{~mm}$ of height. Five $\mathrm{K}$ type thermocouples and a datalogger instrumented the experimental set-up. Two thermocouples were located inside the PCM module (one in the centre and another one at half distance between the first one and the metal container). The other ones were situated inside the water, outside the PCM module, one of them in contact with the external surface of it. The distance between the inside water thermocouples was $50 \mathrm{~mm}$, and all thermocouples were at $135 \mathrm{~mm}$ distance of the top of the tank. Fig. 2 illustrates the instrumentation of the experiments.

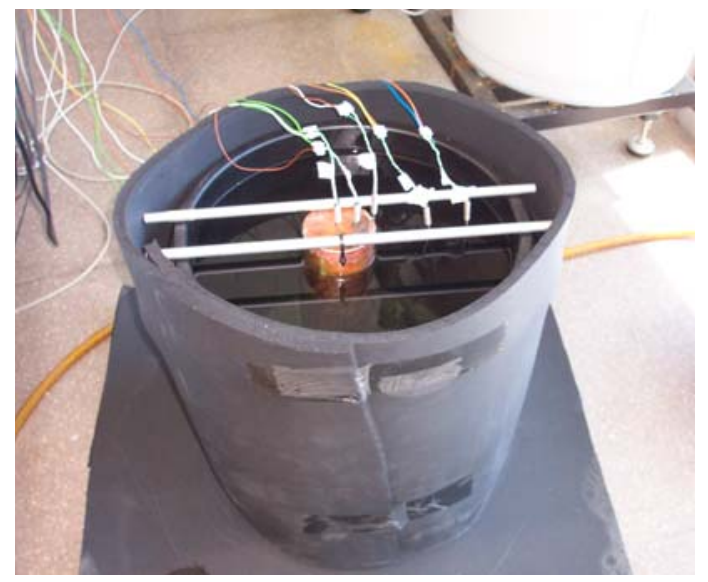

Fig. 2. Instrumentation of the experimental work.

The modules, containing melted $\mathrm{PCM}$ at $70^{\circ} \mathrm{C}$, were introduced into the cold water tank to evaluate the heat transfer phenomena. The experiment was stopped when PCM and water temperatures were the same.

The PCM-graphite composite used was sodium acetate trihydrate with graphite $(90: 10$ vol.\%). This product has a melting point of $58^{\circ} \mathrm{C}$, melting enthalpy between 180 and $200 \mathrm{~kJ} / \mathrm{kg}$, density between 1,35 and $1,4 \mathrm{~kg} / \mathrm{L}$, heat capacity of 2,5 $\mathrm{kJ} / \mathrm{kg} \cdot \mathrm{K}$, and thermal conductivity between 2 and 5 $\mathrm{W} / \mathrm{m} \cdot \mathrm{K}$. 


\section{Results and discussion}

The experimental results show an increase in the heat transfer rate when using PCM modules with vertical fins. This effect is a result of the increase of the heat transfer area and the heat transfer coefficient for natural convection.

The heat transfer coefficient for natural convection for each PCM module geometry is determined and compared in Fig. 3. The use of fins increased significantly that coefficient, achieving heat transfer coefficients up to 3 times larger than the ones without fins.

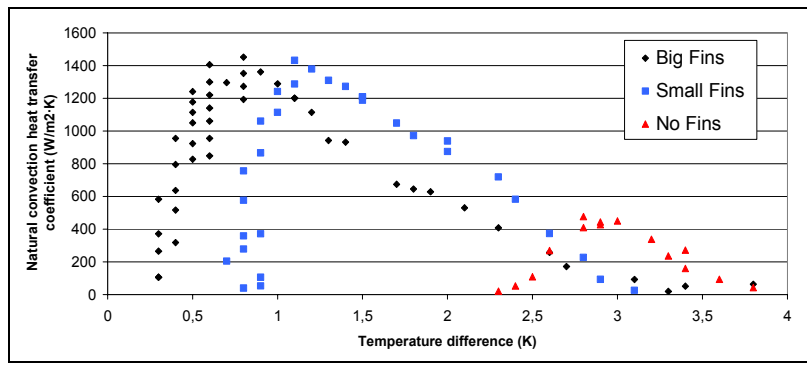

Fig. 3. Comparison of the natural convection heat transfer coefficient for different PCM modules.

An important characteristic in a storage tank connected to a solar system is the time needed to heat the water to a useful temperature. This time is reduced by using external vertical fins in the PCM module.

Fig. 4 shows the time needed to cool down a PCM module without fins from $60^{\circ} \mathrm{C}$ to $45^{\circ} \mathrm{C}$, while Fig. 5 shows the same results for a PCM module with 20 $\mathrm{mm}$ fins. Finally, the results of the experiments using a PCM module with $40 \mathrm{~mm}$ fins are presented in Fig. 6.

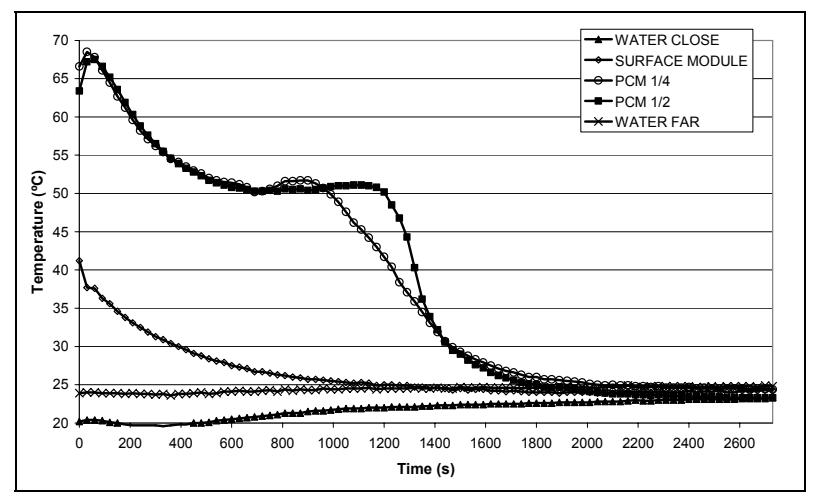

Fig. 4. Water and PCM temperature over time of experimental work using a PCM module without fins.

The time necessary for the cooling down process is presented in Table I. When adding $20 \mathrm{~mm}$ fins, the time reduction was about $23,53 \%$, while when using $40 \mathrm{~mm}$ fins, this reduction reaches $58,82 \%$.

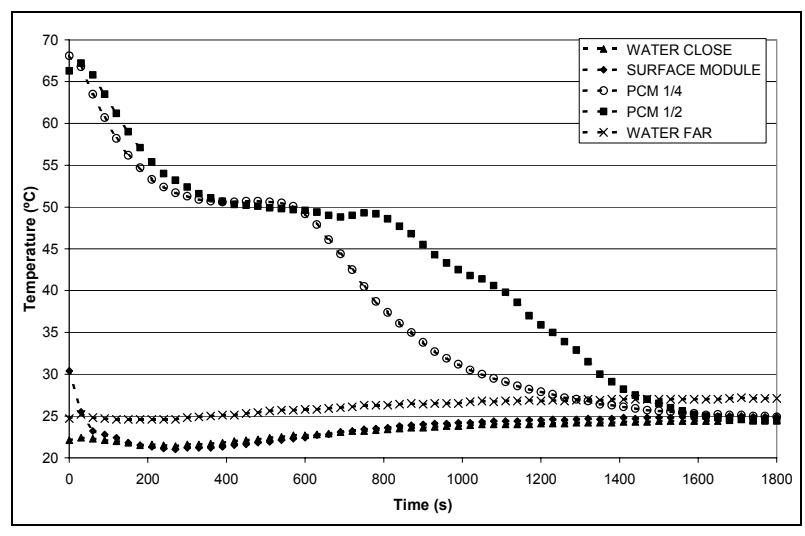

Fig. 5. Water and PCM temperature over time of experimental work using a PCM module with vertical external fins of $20 \mathrm{~mm}$ length.

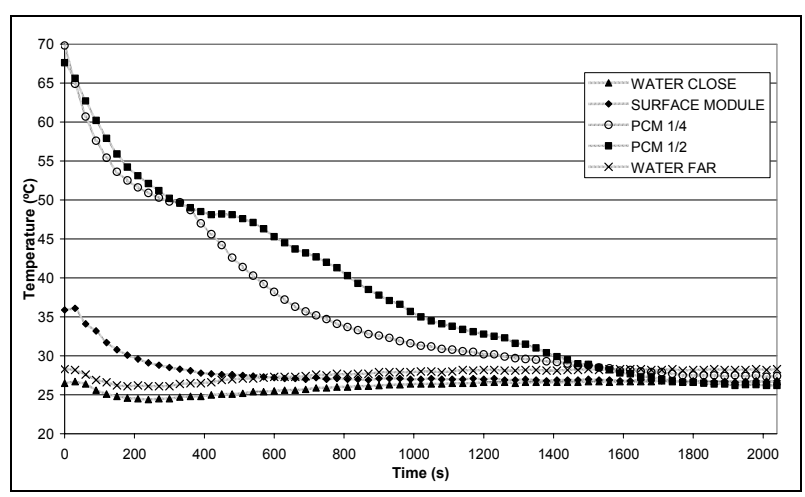

Fig. 6. Water and PCM temperature over time of experimental work using a PCM module with vertical external fins of $40 \mathrm{~mm}$ length.

Table I. Reduction of the time necessary to solidify the PCM.

\begin{tabular}{|l|c|c|c|}
\hline \multicolumn{1}{|c|}{ Parameter } & $\begin{array}{c}\text { Without } \\
\text { Fins }\end{array}$ & $\begin{array}{c}\mathbf{2 0} \mathbf{~ m m} \\
\text { Fins }\end{array}$ & $\begin{array}{c}\mathbf{4 0} \mathbf{~ m m} \\
\text { Fins }\end{array}$ \\
\hline Initial Temp $\left({ }^{\circ} \mathrm{C}\right)$ & 60 & 59 & 60,1 \\
\hline Final Temp $\left({ }^{\circ} \mathrm{C}\right)$ & 46,3 & 45,5 & 45,5 \\
\hline$\Delta \mathrm{T}\left({ }^{\circ} \mathrm{C}\right)$ & 13,7 & 13,5 & 14,6 \\
\hline Initial Time & $12: 43$ & $12: 41$ & $12: 41$ \\
\hline Final Time & $13: 00$ & $12: 54$ & $12: 48$ \\
\hline $\mathbf{\Delta t}$ (minutes) & $\mathbf{1 7}$ & $\mathbf{1 3}$ & $\mathbf{7}$ \\
\hline
\end{tabular}

Using bigger fins allows achieving the highest heat transfer coefficient value with a lower temperature difference in comparison with the smaller ones. Analyzing the obtained results, experimental correlations can be determined for each specific geometry. These equations ( 1 and 2 ) provide the heat transfer coefficient for natural convection as a function of the temperature difference of the system.

For $20 \mathrm{~mm}$ fins, the experimental correlation is shown in Equation 1, and for $40 \mathrm{~mm}$ fins, the experimental correlation is presented in Equation 2. Using these correlations for the simulation of the solar system, the results obtained showed a faster heat transfer rate from the PCM to the water when using finned PCM modules. Fig. 7 presents the comparison of the temperature of the water in the 
experimental work (without fins) and the ones obtained simulating PCM modules with vertical fins.

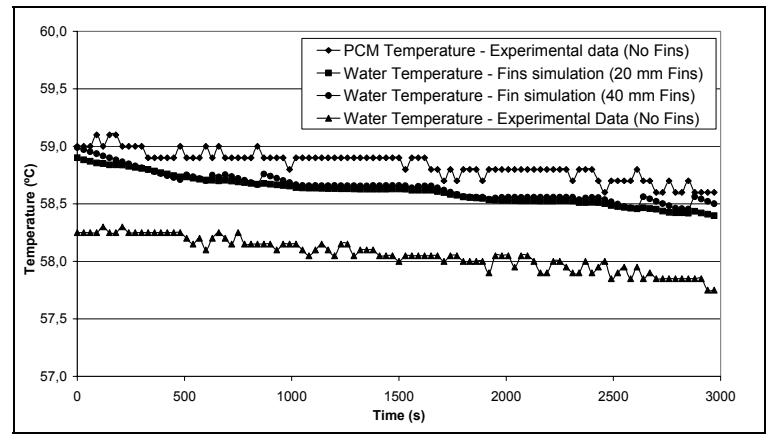

Fig. 7. Comparison between experimental and simulated results from the solar system using PCM modules with and without fins.

\section{Numerical solution}

To compare the behaviour of the system using finned PCM modules with another one without fins, two numerical codes were implemented.

The first one simulated the storage system with PCM modules without fins. This code consisted in the energy balance presented before simulating a long time working conditions.

The results obtained from the simulation were compared with the experimental ones to validate the numerical code.

The second code was used to simulate the storage tank with finned PCM modules. To simulate the energy balance of the system, the natural convection heat transfer coefficient obtained from the experimental set-up was used. As in the first case, the code was validated comparing the numerical results with the experimental ones.

Once both numerical codes were validated, the heating of the water was studied in order to determine the improvement achieved by attaching external vertical fins in the PCM modules.

\section{Experimental correlations}

Experimental correlations to evaluate Nusselt number have been obtained as a function of Rayleigh number for each geometry.

The geometry studied in this paper consists in a cylindrical module of $88 \mathrm{~mm}$ of diameter and 315 $\mathrm{mm}$ height with external vertical fins of $310 \mathrm{~mm}$ height and 20 and $40 \mathrm{~mm}$ length situated in the middle upper part of a cylindrical plastic water tank of $440 \mathrm{~mm}$ of diameter and $450 \mathrm{~mm}$ height.

Different correlations were analysed to find which one fits better to the experimental data. Three dimensionless numbers (Rayleigh, Prandtl,
Grashof) and several combinations of them were used.

First analysis consisted in plotting Nusselt number as a function of Rayleigh number for each geometry, as showed in Fig 8 and Fig 9. The obtained correlations are Equation 3 for $20 \mathrm{~mm}$ fins, and Equation 4 for $40 \mathrm{~mm}$ fins.

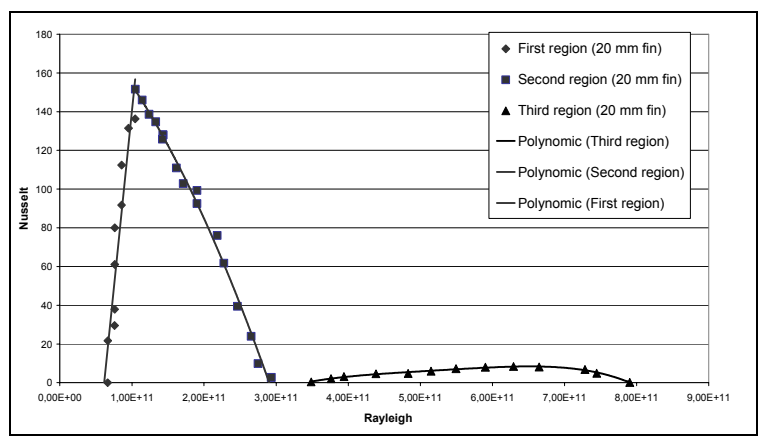

Fig. 8. Experimental correlation of Nusselt number over Rayleigh for a PCM module with $20 \mathrm{~mm}$ fins.

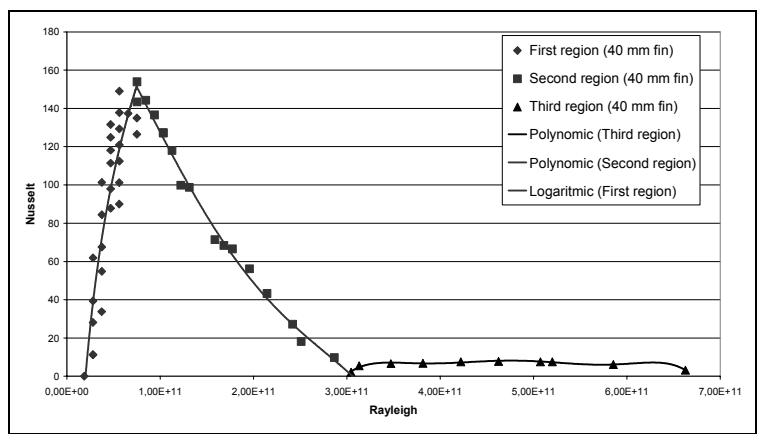

Fig. 9. Experimental correlation of Nusselt number over Rayleigh for a PCM module with $40 \mathrm{~mm}$ fins.

Nusselt over powered Rayleigh was studied. In Fig. 10 and Fig. 11 Nusselt as a function of Rayleigh powered to $1 / 4$ is represented. The experimental correlations are Equation 5 for $20 \mathrm{~mm}$ fins, and Equation 6 for $40 \mathrm{~mm}$ fins.

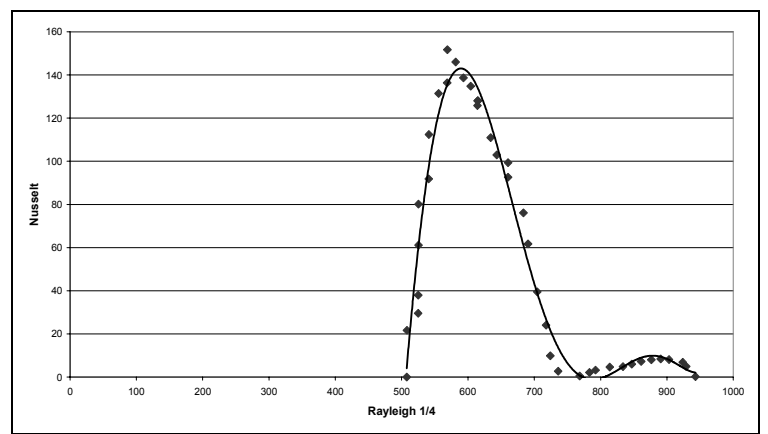

Fig. 10. Experimental correlation of Nusselt number over Rayleigh powered to $1 / 4$ for a PCM module with $20 \mathrm{~mm}$ fins. 


$$
\begin{aligned}
& \left\{\begin{array}{lrl}
h_{P C M}=-5.281,3 \cdot \Delta T^{3}+12.000 \cdot \Delta T^{2}-5.602,9 \cdot \Delta T & & 0 \leq \Delta T<1,3 \\
h_{P C M}=368,48 \cdot \Delta T^{4}-3.171,3 \cdot \Delta T^{3}+9.828,9 \cdot \Delta T^{2}-13.688 \cdot \Delta T+8.438 & 1,3 \leq \Delta T<2,9 \\
h_{P C M}=0,1659 \cdot \Delta T^{5}-6,0142 \cdot \Delta T^{4}+82,712 \cdot \Delta T^{3}-548,72 \cdot \Delta T^{2}+1.790,5 \cdot \Delta T-2.285,7 & 2,9 \leq \Delta T<13
\end{array}\right. \\
& \left\{\begin{array}{lr}
h_{P C M}=21.601 \cdot \Delta T^{4}-46.632 \cdot \Delta T^{3}+31.600 \cdot \Delta T^{2}-4.871,8 \cdot \Delta T & 0 \leq \Delta T \leq 0,9 \\
h_{P C M}=155,74 \cdot \Delta T^{2}-1.199,2 \cdot \Delta T+2.313,2 & 0,9<\Delta T \leq 3,3 \\
h_{P C M}=-2,138 \cdot \Delta T^{6}+71,468 \cdot \Delta T^{5}-979,88 \cdot \Delta T^{4}+7.051,2 \cdot \Delta T^{3}-28.085 \cdot \Delta T^{2}+58.722 \cdot \Delta T-50.309
\end{array}\right. \\
& N u=-1 \cdot 10^{-20} \cdot R a^{2}+5 \cdot 10^{-9} \cdot R a-257,96 \\
& N u=-1 \cdot 10^{-21} \cdot R a^{2}-2 \cdot 10^{-10} \cdot R a+190,81 \\
& N u=-2 \cdot 10^{-45} \cdot R a^{4}+4 \cdot 10^{-33} \cdot R a^{3}-3 \cdot 10^{-21} \cdot R a^{2}+1 \cdot 10^{-9} \cdot R a-158,96 \\
& N u=115,16 \cdot \operatorname{Ln}(R a)-2731,9 \\
& N u=-4 \cdot 10^{-44} \cdot R a^{4}+3 \cdot 10^{-32} \cdot R a^{3}-5 \cdot 10^{-21} \cdot R a^{2}-6 \cdot 10^{-10} \cdot R a+212,28 \\
& N u=-1 \cdot 10^{-66} \cdot R a^{6}+3 \cdot 10^{-54} \cdot R a^{5}-3 \cdot 10^{-42} \cdot R a^{4}+2 \cdot 10^{-30} \cdot R a^{3}- \\
& -7 \cdot 10^{-19} \cdot R a^{2}+1 \cdot 10^{-7} \cdot R a-10273 \\
& 6,65 \cdot 10^{10} \leq R a<1,05 \cdot 10^{11} \\
& 1,05 \cdot 10^{11} \leq R a \leq 2,93 \cdot 10^{11} \\
& 3,49 \cdot 10^{11} \leq R a \leq 7,9 \cdot 10^{11} \\
& 1,87 \cdot 10^{10} \leq R a<7,53 \cdot 10^{10} \\
& 7,53 \cdot 10^{10} \leq R a<3,05 \cdot 10^{11} \\
& 3,05 \cdot 10^{11} \leq R a \leq 6,63 \cdot 10^{11} \\
& N u=1 \cdot 10^{-12} \cdot\left(R a^{1 / 4}\right)^{6}-5 \cdot 10^{-9} \cdot\left(R a^{1 / 4}\right)^{5}+9 \cdot 10^{-6} \cdot\left(R a^{1 / 4}\right)^{4}-0,0084 \cdot\left(R a^{1 / 4}\right)^{3}+4,1867 \cdot\left(R a^{1 / 4}\right)^{2}- \\
& -1070,6 \cdot R a^{1 / 4}+109128 \quad 510 \leq R a^{1 / 4} \leq 770 \text { and } 830 \leq R a^{1 / 4} \leq 945 \\
& N u=5 \cdot 10^{-13} \cdot\left(R a^{1 / 4}\right)^{6}-2 \cdot 10^{-9} \cdot\left(R a^{1 / 4}\right)^{5}+4 \cdot 10^{-6} \cdot\left(R a^{1 / 4}\right)^{4}-0,0034 \cdot\left(R a^{1 / 4}\right)^{3}+1,6085 \cdot\left(R a^{1 / 4}\right)^{2}- \\
& -395,89 \cdot R a^{1 / 4}+39113 \\
& 370 \leq R a^{1 / 4} \leq 900
\end{aligned}
$$

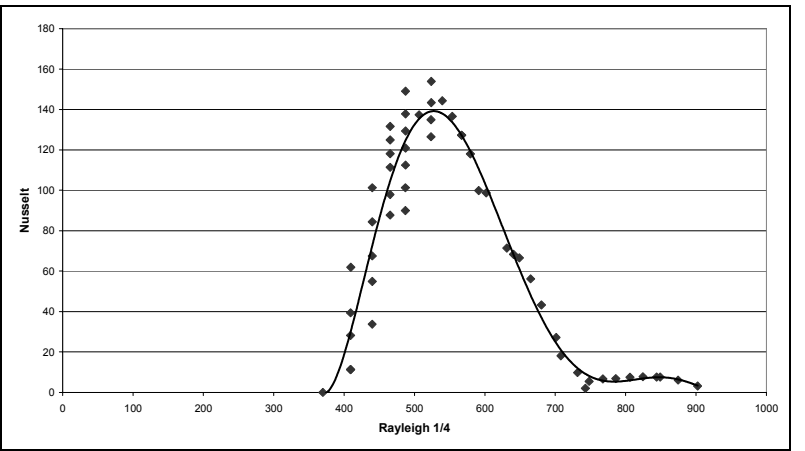

Fig. 11. Experimental correlation of Nusselt number over Rayleigh powered to $1 / 4$ for a PCM module with $40 \mathrm{~mm}$ fins.

Other correlations were also studied.

\section{Conclusions}

The use of external fins in PCM modules increased the heat transfer coefficient and reduced the time necessary for the solidification of the material. The bigger the fins were, the faster was the solidification process and the higher was the heat transfer coefficient.

With this modification, the storage systems with PCM would have a faster availability of the stored energy and would be more flexible to match the hot water availability and demand. This would be a good advantage for the applications of Thermal Energy Storage (TES) in solar systems.

Using experimental results, useful Nusselt correlations in function of Rayleigh number were found to be able to evaluate the natural convection heat transfer coefficient for that specific geometry. These tools would be very useful for numerical simulations to predict the behaviour of a solar system with PCM modules in the storage tank, as in this paper and for other applications with similar geometries.

\section{References}

[1] L.F. Cabeza, M. Ibáñez, C. Solé, J. Roca, M. Nogués, Experimentation with a water tank including a PCM module. Solar Energy Materials and Solar Cells, in press (2006). 
[2] M. Ibáñez, L.F. Cabeza, C. Solé, J. Roca, M. Nogués, Modelization of a water tank including a PCM module. Applied Thermal Engineering, in press (2006).

[3] M. Nogués, L.F. Cabeza, J. Roca, J. Illa, B. Zalba, J.M. Marín, S. Hiebler, H. Mehling, Efecto de la Inserción de un Módulo de PCM en un Depósito de ACS. Anales de la Ingeniería Mecánica, vol 1 (2002) 398-402.

[4] L.F. Cabeza, H. Mehling, S. Hiebler, F. Ziegler, Heat transfer enhancement in water when used as PCM in thermal energy storage, Applied Thermal Engineering 22 (2002) 1141-1151.

[5] Esmail M.A. Mokheimer, Performance of annular fins with different profiles subject to variable heat transfer coefficient, Int. J. Heat and Mass Transfer 45 (2002) 3631-3642.

[6] D.R. Harper, W.B. Brown, Mathematical Equations for Heat Conduction in the Fins of Air-Cooled Engines, National Advisory Committee for Aeronautics, Report no. 158, 1922.

[7] E. Schmidt, die Warmeübertragung durch Rippen, Zeit. V.D.I. 70 (1926) 885-889, see pp. 947-951.

[8] R. Focke, Die Nadel als Kühlelemente, Forsch. Geb. Ingenieurw. 13 (1942) 34-42.

[9] W.M. Murray, Heat dissipation through an annular disk or fin of uniform thickness, J. Appl. Mech. Trans. ASME 60 (1938) A-78.

[10] W.H. Carrier, S.W. Anderson, the resistance to heat flow through finned tubing, Heat. Piping air cond. 10 (1944) 304-320.

[11] Avrami Melvin, J.B. Little, Diffusion of heat through a rectangular bar and the cooling and insulating effect of fins, I. The steady state, J. Appl. Phys. 13 (1942) 225264.

[12] K.A. Gardner, Heat exchanger tube sheet temperature, Refiner Nat. Gasoline Manuf. 21 (1942) 7177.

[13] K.A. Gardner, Efficiency of extended surface, Trans. ASME, J. Heat Transfer 67 (1945) 621-631.

[14] A. Ullmann, H. Kalman, Efficiency and optimized dimensions of annular fins of different cross-section shapes, Int. J. Heat Mass Transfer 32 (6) (1989) 11051110.

[15] R. Karaback, The effect of fin parameter on the radiation and free convection from a finned horizontal cylindrical heater, Energy Convers. Mgmt. 33 (11) (1992) 997-1005.

[16] A. Campo, L. Harrison, Prediction of safe tip temperature in uniform annular fins for the design of thermal exchange equipment via symbolic mathematics, Int. Commun. Heat Mass Transfer 21 (4) (1994) 531-538.

[17] P. Razelos, K. Imre, The optimum dimensions of circular fins with variable thermal parameters, Trans. ASME, J. Heat Transfer 102 (1980) 420-425.
[18] K. Laor, H. Kalman, Performance and optimum dimensions of different cooling fins with a temperature dependent heat transfer coefficient, Int. J. Heat Mass Transfer 39 (9) (1996) 1993-2003.

[19] S.M. Zubair, A.Z. Al-garni, J.S. Nizami, The optimal dimensions of circular fins with variable profile and temperature-dependent thermal conductivity, Int. J. Heat Mass Transfer 39 (16) (1996) 3431-3439.

[20] H.C. Unal, Determinationof the temperature distribution in an extended surface with a non-uniform heat transfer coefficient, Int. J. Heat Mass Transfer 28 (12) (1985) 2270-2284.

[21] A.K. Sen, S. Trinh, An exact solution for the rate of heat transfer from rectangular fin governed by a power law-type temperature dependence, Trans. ASME, J. Heat Transfer 108 (1986) 457-459.

[22] A. Campo, R.E. Stuffle, Symbolic mathematics for calculation of thermal efficiencies and tip temperatures in annular fins of uniform thickness, int. j. Heat Mass Transfer 40 (2) (1996) 490-492.

[23] Lien-Tsaiyu, Cha'o Kuang Chen, Application of the taylor transformation to the transient temperature response of an annular fin, Heat Transfer Eng. 20 (1) (1999) 78-87.

[24] H. Mehling, L.F. Cabeza, S. Hippeli, S. Hiebler, PCMmodule to improve hot water heat stores with stratification. Renewable Energy 28 (2003) 699-711.

[25] L.F. Cabeza, M. Nogues, J. Roca, J. Illa, S. Hiebler, $\mathrm{H}$. Mehling, PCM-module to improve hot water heat stores with stratification: first tests in a complete solar system, in: R. Dománski, M. Jaworski, M. Rebow, ed., 9th International Conference on Thermal Energy Storage, vol. 1 (Institute of Heat Engineering, 2003) 273-278. 